\title{
Growth of White Spruce, Picea glauca, Seedlings in Relation to Microenvironmental Conditions in a Forest-Prairie Ecotone of Southwestern Manitoba
}

\author{
SOPHAN CHHIN ${ }^{1}$ and G. GeOFF WANG ${ }^{2}$ \\ ${ }^{1}$ Corresponding author: Department of Forestry, Michigan State University, East Lansing, Michigan 48824-1222 USA \\ ${ }^{2}$ Department of Forestry and Natural Resources, Clemson University, 261 Lehotsky Hall, Clemson, South Carolina $29634-0317$ \\ USA; e-mail: gwang@clemson.edu
}

Chhin, Sophan, and G. Geoff Wang. 2007. Growth of White Spruce, Picea glauca, seedlings in relation to microenvironmental conditions in a forest-prairie ecotone of southwestern Manitoba. Canadian Field-Naturalist 121(2): 191-200.

The influence of microenvironmental conditions on the growth performance (i.e., diameter and height growth) of White Spruce [Picea glauca (Moench) Voss] seedlings was examined within three contrasting habitats: White Spruce tree islands, open prairies and Trembling Aspen (Populus tremuloides Michx.) groves. These habitats exist within a disjunct occurrence of White Spruce at its southern limit of distribution in three mixed-grass prairie preserves in the Spruce Woods Provincial Park within the forest-prairie ecotone of southwestern Manitoba. Microenvironmental measurements (i.e., light, temperature, relative humidity, soil moisture) were obtained on 10 sites in each of the three habitats and growth characteristics of 60 White Spruce seedlings were measured in each of three habitats. Higher light and soil temperature conditions occurred within the open prairie. In contrast, lower light and soil temperature conditions occurred under the tree canopy of aspen groves and the northern aspect of spruce islands, which moderated the effect of the dry regional climate. Height growth did not vary significantly among the three habitats. The greater diameter growth and decreased slenderness of White Spruce seedlings in the open versus the shaded habitats appears to be a result of increased photosynthesis at higher light intensity and may also represent a morphological adaptation to withstand the effect of increased wind exposure. The increased slenderness of White Spruce in the shaded habitats appears to be a morphological adaptation of increasing carbon allocation towards height growth and thus maximizing effective competition for light.

Key Words: White Spruce, Picea glauca, prairie-forest boundary, aspen parkland, growth, microenvironment, seed-seedling conflicts, Manitoba.

In the prairie provinces of Canada, the southern limit of conifer species occurs in the aspen parkland. Vegetation in the aspen parkland is dominated by Trembling Aspen (Populus tremuloides Michx.) which exists as continuous forest or as groves intermixed with prairie (Bird 1961). The aspen parkland is a transitional vegetation zone (ecotone) between prairie to the south and boreal forest to the north (Bird 1961; Zoltai 1975). The prevailing regional climate of the aspen parkland and mixed-grass prairie in southwestern Manitoba is characterized by low precipitation, high summer temperatures, and dry winds, any of which may be limiting factors to plant distribution and growth (Coupland 1950). For instance, previous studies which examined the radial growth-climate association of White Spruce [Picea glauca (Moench) Voss] in the aspen parkland region demonstrated that growth was restricted by moisture deficiency exacerbated by temperature-induced drought stress (Chhin et al. 2004).

Tree invasion into prairies under the dry climate of the aspen parkland must be assisted by favorable microenvironments or "safe sites" (Harper 1977; De Steven 1991a, 1991b; Kellman and Kading 1992; Chhin and Wang 2002). In many prairie environments, shrubs are known to facilitate tree seedling establishment (Callaway 1995; Chambers 2001) by suppressing grass com- petition (Bird 1961; Werner and Harbeck 1982) and by providing protective conditions from abiotic forces such as fire (Coupland 1950; Bird 1961). The presence of previously established trees in open prairie not only reduces evaporative water loss from plants (Kellman and Kading 1992) but also increases soil moisture and nutrients (Wilson and Kleb 1996; Li and Wilson 1998; Wilson 1998). Furthermore, woody canopies modify the understory microclimate, including shading, interception of precipitation, litter fall (Vetaas 1992), reduced wind speed (Archibold et al. 1996), lower soil temperature, and higher humidity (Carlson and Groot 1997).

Within the aspen parkland of southwestern Manitoba, White Spruce typically establishes under a Trembling Aspen canopy and will eventually replace aspen to form White Spruce forests in the absence of disturbances (Bird 1961). Abundant White Spruce seedlings and saplings are commonly observed in many Trembling Aspen stands, indicating a favorable environment for regeneration. However, White Spruce can occasionally invade open prairies within previously established Creeping Juniper (Juniperus horizontalis Moench) patches (Bird 1961; Chhin and Wang 2002). Creeping Juniper is believed to reduce mortality of White Spruce seedlings from prairie ground fires (Bird 1961). The progressive recruitment and establishment of White 
Spruce in the open prairie results in the development of White Spruce tree islands which are surrounded by mixed-grass prairie. The islands have an asymmetric spatial structure since White Spruce regeneration is concentrated on the northern aspect of the tree islands. Chhin and Wang (2002) determined that the best environment for White Spruce regeneration within mixed-grass prairie was under the influence of established White Spruce trees (i.e., on the north vs. south aspect and between 4 to $12 \mathrm{~m}$ from the spruce island centre, and close association with Creeping Juniper). Other studies have also observed growth of White Spruce in the aspen parkland region on favourable microenvironments such as the north side of trees, north side of river valleys, and other north-facing slopes and microsites (Zoltai 1975; Hogg 1994; Hogg and Schwartz 1997). Together, these previous studies suggested that the suitability for White Spruce establishment decreased from aspen groves (i.e., under a Trembling Aspen canopy), to White Spruce tree islands (i.e., under the influence of established White Spruce trees) and to Creeping Juniper patches in open prairies. However, environmental conditions associated with these habitats have not been documented and how White Spruce growth differs among these habitats has not been quantified.

Ecotones are expected to be sensitive to climatic change, and the environment of the aspen parkland is believed to characterize the future boreal forest under a warmer climate (Hogg 1994). Moderated microenvironmental conditions may potentially serve as microscale refugia or "safe sites" (Harper 1977) for tree seedlings in the context of global warming during the $21^{\text {st }}$ century (IPCC 2007) within a climatically sensitive ecotonal region of the aspen parkland. The first objective of this study was to examine the microenvironmental conditions of five habitats within the aspen parkland of the Spruce Woods Provincial Park (SWPP) in southwestern Manitoba, Canada. These habitats include one habitat in Trembling Aspen groves (AG) [interior (AG-I)], two habitats in White Spruce tree islands (SI) [northern (SI-N) vs. southern (SI-S) aspect], and adjacent to the islands, two habitats in open prairies (OP) [ground vegetation dominated by grass (OP-G) vs. juniper (OP-J)]. The second objective of the study was to compare White Spruce seedling growth (i.e., height and diameter) among three habitats (OP-J, SI$\mathrm{N}$, and AG-I; seedlings were not sampled in OP-G and SI-S since it was extremely rare to find them in these habitats) and relate growth patterns to the microenvironmental patterns.

\section{Methods \\ Study area}

The study was conducted in the SWPP which is located in southwestern Manitoba $\left(49^{\circ} 40^{\prime} \mathrm{N}, 9^{\circ} 15^{\prime} \mathrm{W}\right)$ (Figure 1). The nearest meteorological station with a long-term climatic record is the Brandon Agriculture
Station $\left(49^{\circ} 52^{\prime} \mathrm{N}, 99^{\circ} 59^{\prime} \mathrm{W}\right)$, which is located about $88.5 \mathrm{~km}$ northwest of the SWPP. The area experienced, for the reference period of 1971-2000, an average annual temperature of $2.4^{\circ} \mathrm{C}$ (Environment Canada 2002). Average annual precipitation amounts to $474.0 \mathrm{~mm}$, with $78.3 \%$ as rainfall and the remainder as snowfall. Precipitation peaks in June $(75.7 \mathrm{~mm})$, and temperature is highest in July, reaching a daily mean of $18.9^{\circ} \mathrm{C}$ (Environment Canada 2002). Vegetation in the park is characterized as the aspen-oak grove of the boreal forest region (Rowe 1972). A sandhill, mixed-grass prairie community unique to the aspen parkland is located in the SWPP and consists of Trembling Aspen intermixed with a disjunct population of White Spruce at its southern limit of distribution (Schykulski and Moore 1997). The SWPP resides over an extensive belt of deltaic sands $\left(6500 \mathrm{~km}^{2}\right)$ created 12000 years B.P. when a predecessor of the Assiniboine River flowed into glacial Lake Agassiz. The SWPP is located on this delta, and this area has been designated as the Assiniboine Delta Natural Region (ADNR). Within the ADNR, the SWPP contains some of the best examples of the few remaining remnants of native mixedgrass prairie, since most of the native prairie in the ADNR has been lost to agricultural cultivation. The mixed-grass prairie preserves of the SWPP are protected under the mandate of the Prairie Management Plan of Manitoba Conservation in order to preserve its unique and rich biodiversity of plants, insects, and wildlife (Schykulski and Moore 1997).

Natural and anthropogenic disturbances have contributed to the landscape mosaic of the aspen parkland (Bird 1961). In pre-European settlement times, disturbances included fire which occurred naturally or started by Native people in order to maintain the prairie environment for the Bison (Bison bison L.). Grazing by herbivores such as Bison and Elk (Cervus canadensis Erxl.) prevented the encroachment of the forest onto the prairie. European settlement contributed to the decline of the Bison population due to hunting, livestock grazing, intensive agriculture, and the policy of fire suppression (Bird 1961). The reduction of grazing and fire pressure has resulted in the encroachment of the forest onto the prairie. A policy of fire suppression continues within the SWPP, with intermittent prescribed burning permitted within the mixed-grass prairie preserves (Schykulski and Moore 1997).

\section{Site selection}

The study was located in three mixed-grass prairie preserves north of the Assiniboine river: Picnic, Aspen Bluff, and Jackfish prairie (Figure 1). Ten White Spruce islands (SI) with adjacent open prairie (OP), and ten aspen groves (AG) were selected using aerial photographs and field reconnaissance. Four sites of each habitat were chosen in Picnic prairie and Aspen Bluff prairie, whereas two sites of each habitat were selected in Jackfish prairie. Although the occurrence of habitat types could be confounded with environmental con- 


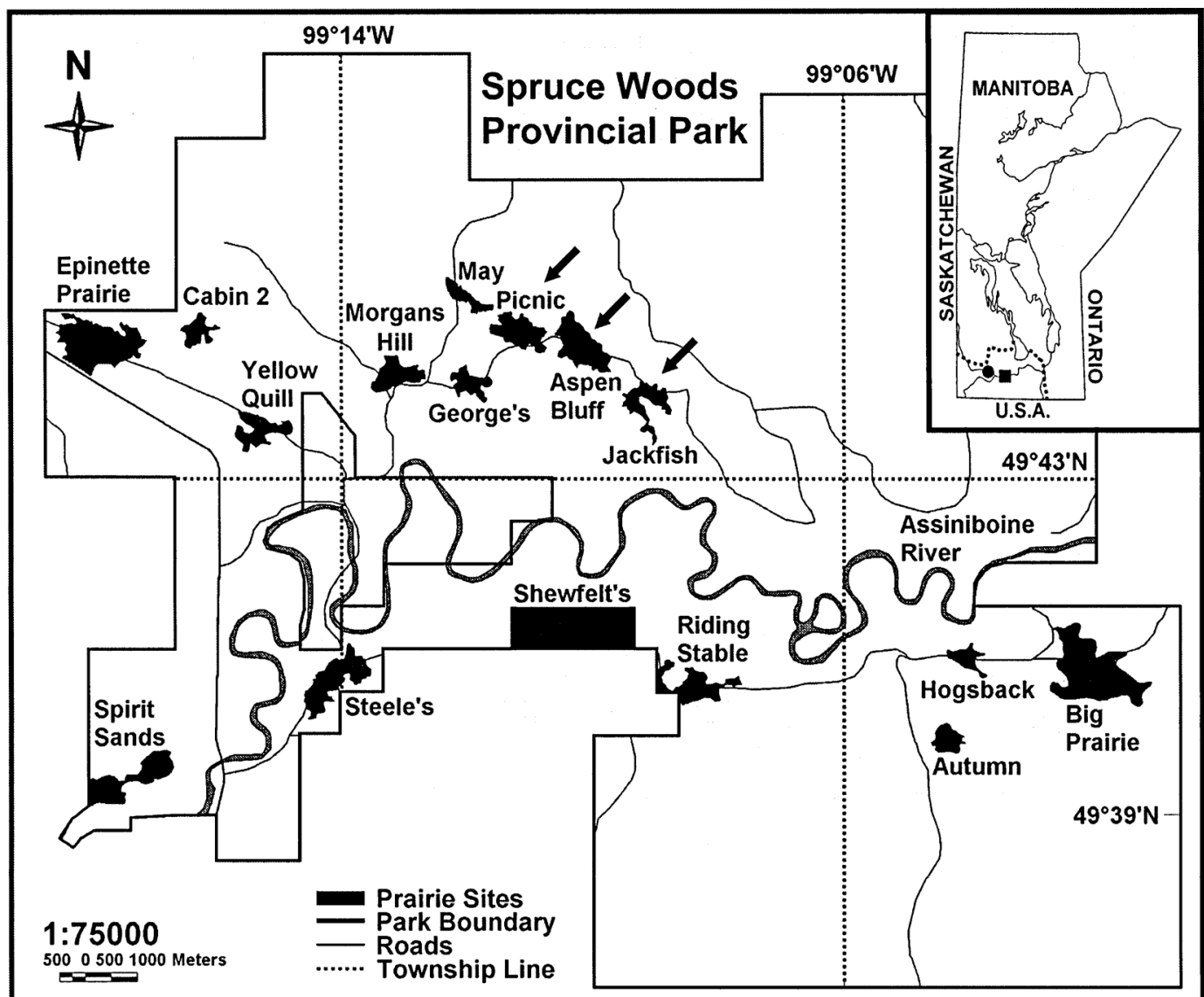

FIGURE 1. Regional setting of the Spruce Woods Provincial Park (SWPP) (ロ) and the city of Brandon (•) in southwestern Manitoba shown in the inset map. The southern continuous limit of White Spruce according to Farrar (1995) is indicated by the dashed line. The arrows in the enlarged map of the SWPP indicate the mixed-grass prairie preserves in which the study was conducted. Adapted from Schykulski and Moore (1997).

ditions not sampled, the study area is comprised of homogeneous soil conditions which minimize the degree of confounding (Schykulski and Moore 1997). The soil is uniformly sandy and nutrient poor with a poorly developed thin organic layer. Furthermore, it was ensured that sites selected occurred on uniformally flat topography. Additional criteria for spruce island selection were that islands be at least $20 \mathrm{~m}$ apart from each other or from the forest edge. Open prairie containing patches of grass and Creeping Juniper were selected adjacent to but at least $20 \mathrm{~m}$ away from a spruce island or forest edge. Aspen groves containing understory development of juvenile White Spruce were selected.

\section{Sampling design}

The sampling design in a White Spruce island consisted of extending a $12 \mathrm{~m}$ transect line on each of the north and south side of a reference tree (i.e., the largest dominant tree of the spruce island). One habitat was selected on the northern (SI-N) and one on the southern (SI-S) aspect of each spruce island. Each SI$\mathrm{N}$ and SI-S habitat was represented by three circular plots (one-meter radius). The centres of the three plots corresponding to each of the SI-N and SI-S habitat were placed 4,8 , and $12 \mathrm{~m}$ from the reference tree. Two habitats, a grass habitat (OP-G) and a juniper habitat (OP-J), were selected in open prairie adjacent to White Spruce islands. Each OP-G and OP-J habitat was represented by three randomly placed circular plots (one-meter radius). One habitat was selected in the interior of each Trembling Aspen grove (AG-I) such that there was at least a ten meter buffer zone to the aspen stand edge. The AG-I habitat was represented by six randomly placed circular plots (one-meter radius). Two different habitats were sampled in spruce islands and open prairies because previous studies clearly indicated differences in the establishment of White Spruce seedlings (Chhin and Wang 2002). OP-G generally had no seedling establishment while OP-J occa- 
sionally supported seedlings. Many more seedlings were found in SI-N (0.22 seedlings $\left.\mathrm{m}^{-2}\right)$ compared to SI-S $\left(0.008\right.$ seedlings $\left.\mathrm{m}^{-2}\right)$.

\section{Data collection}

\section{Microenvironment}

Solar radiation was measured in the morning (10:00 - 12:00 h) and afternoon (14:00 - 16:00 h) with an AccuPAR Ceptometer (Decagon Devices, Pullman, USA). Measurements for these two periods were averaged. Light measurements were taken at a height of $1.3 \mathrm{~m}$ from the north, east, south and west sides of each circular plot. Light intensity of each circular plot was expressed as an average of these four measurements. Light intensities in spruce islands and aspen groves were expressed as percentages of the average light intensity of the open prairie.

Air temperature and relative air humidity $(15 \mathrm{~cm}$ above ground) were measured using digital thermohygrometers (sensor size: $1 \mathrm{~cm}$ diameter) (Barnant, Barrington, USA). Soil (15 cm below the surface) temperature was measured with a thermocouple penetration probe (sensor size: $0.5 \mathrm{~cm}$ diameter ) and surface temperature was measured with a thermocouple surface probe (sensor size: $1.25 \mathrm{~cm}$ diameter) (Barnant, Barrington, USA). These measurements were taken in the centre of each plot and were measured once between 10:00 and 16:00 $\mathrm{h}$.

Surface soil moisture was measured at the centre of each plot with a digital Theta probe soil moisture sensor (Delta-T Devices, Cambridge, UK). The prongs of the Theta probe have a length of $6 \mathrm{~cm}$ and thus measure soil moisture of the mineral soil within the top $6 \mathrm{~cm}$. A profile probe was used to measure soil moisture of the mineral soil within the top $40 \mathrm{~cm}$ with sensors positioned at the depths of 10,20,30 and $40 \mathrm{~cm}$ below the soil surface (Delta-T Devices, Cambridge, UK). The profile measurements were taken in an augered hole near the centre of each plot. Due to the limitations in time and instrumentation, not all plots of each habitat could be sampled. Thus, in spruce islands, profile measurements were taken in a single plot $8 \mathrm{~m}$ from the reference tree in each of the SI-N and SI-S habitat. One plot of each juniper habitat and one plot of each grass habitat were randomly selected for measurements in each open prairie site. Two plots of the aspen grove interior habitat were randomly selected from each aspen grove. Three profile readings were taken at each plot by rotating the profile probe $120^{\circ}$ after each individual reading (Delta-T Devices, Cambridge, UK). The profile measurements of each plot were expressed as an average of these three measurements. Surface and profile moisture measurements were taken between 10:00 and 16:00 h.

All microenvironmental variables were measured on sunny clear days at least 24 hours after any rainfall. These conditions ensured that the habitats were contrasted as much as possible. Profile soil moisture was measured on 4 June 2002. Temperature (soil, surface and air), relative air humidity and surface soil moisture were measured on 5 June 2002. Light intensity was measured on 8 July 2002 . The midsummer months of June and July represent typical growing season conditions, and previous studies indicated that precipitation and mean and maximum temperature in the months of June and July strongly affected White Spruce growth (Chhin et al. 2004).

\section{Seedling growth}

Six seedlings $(<2 \mathrm{~m}$ tall $)$ were destructively sampled from each of the same 10 spruce islands and 10 aspen groves used to collect the microenvironmental data. For each of the three circular plots in the northern aspect (i.e., SI-N habitat) of spruce islands, two seedlings which were nearest to the centre of a circular plot were selected for sampling. Similarly, for each of the six circular plots within aspen groves, one seedling nearest to the centre of a circular plot was selected for sampling. As the open prairie sites used to collect the microenvironmental data did not contain sufficient recruitment of White Spruce, each of the three prairie preserves was surveyed and a total of ten sampling locations were selected which contained greater than six seedlings clustered within a circular area of $10 \mathrm{~m}$ radius. Four sampling locations were chosen in Picnic prairie and Aspen Bluff prairie, whereas two sampling locations were selected in Jackfish prairie. The sampling locations were also at least $20 \mathrm{~m}$ from the forest edge, White Spruce tree islands or Trembling Aspen groves. At each sampling location within the prairie preserves, the seedling nearest to six randomly chosen points was selected for sampling. All seedlings collected in spruce islands and open prairies were growing within juniper patches.

Height and root collar diameter (RCD) were recorded for each seedling. A section was taken from the root collar of each destructively sampled seedling. Each root collar section was prepared following standard dendrochronological techniques (Yamaguchi 1991; Stokes and Smiley 1996). That is, all wood samples were sanded with progressively finer grades of sandpaper to highlight ring-width patterns. All root collar sections were crossdated under a binocular microscope to ensure accuracy of age determination.

\section{Data analysis}

\section{Microenvironment}

The Theta probe and profile probe measures the volumetric soil moisture content $(\theta)$ which is the ratio between the volume of water present and the total volume of the soil sample. For the Theta probe measurements, units of soil moisture in $\theta$ are proportional to voltage $(V)$ via the following linear relationship (DeltaT Devices, Cambridge, UK):

$$
\text { [1] } \quad \theta=\frac{[1.1+4.44 \mathrm{~V}]-a_{0}}{a_{1}}
$$

where $a_{0}$ and $a_{l}$ represent constants which characterize different soil types. Based on a large number of soil samples, generalized values of the parameters 
are $a_{0}=1.6$ and $a_{l}=8.4$ for mineral soils (Delta-T Devices, Cambridge, UK); the value of these constants was used in converting the soil moisture of the mineral surface layer from units in $V$ to $\theta$. Similarly, for the profile probe measurements, the following linear relationship was used to convert the soil moisture of the mineral soil at the depths of $10,20,30$ and $40 \mathrm{~cm}$ below the soil surface from units in $V$ to $\theta$ (Delta-T Devices, Cambridge, UK):

$$
\text { [2] } \quad \theta=\frac{[0.67+10.8 \mathrm{~V}]-a_{0}}{a_{1}}
$$

where the generalized constants for mineral soils are $a_{0}=1.6$ and $a_{1}=8.4$ (Delta-T Devices, Cambridge, UK). Volumetric moisture content is a dimensionless parameter expressed as a percentage $(\% \mathrm{vol})$ or as a ratio $\left(\mathrm{m}^{3} \mathrm{~m}^{-3}\right)$. Equations $1(\theta<50 \% \mathrm{vol})$ and $2(\theta<30 \%$ vol) are suitable to convert moisture readings in $V$ to $\%$ vol for soils of low moisture content, which was the case in this study.

For the subsequent statistical analyses, the microenvironmental variables measured in habitats represented by more than one plot were treated as subsamples and were averaged. Except for the temperature data, all microenvironmental parameters with percentage data were $\log$-transformed $\left(\mathrm{LOG}_{10} \mathrm{X}\right)$. Those variables with zero values were log-transformed using: $\mathrm{LOG}_{10}(\mathrm{X}+1)$. Analysis of variance (ANOVA) followed by Tukey's multiple comparisons (Wilkinson 1990) was conducted on the light data to compare light conditions among the five habitats (SI-N, SI-S, OP-G, OP-J and AG-I) with ten replicates for each habitat. Similarly, ANOVA was conducted on surface, soil and air temperature; relative humidity; surface moisture; and average moisture of all profile depths in order to compare these parameters among the five habitats. For the logtransformed data, the mean values of the microenvironmental variables for each habitat and the lower and upper limits of a $95 \%$ confidence interval were backtransformed by taking antilogs $\left(10^{\mathrm{X}}\right.$ or $\left.10^{\mathrm{X}}-1\right)$ so that all means and confidence limits could be reported on their original scale of measurement.

\section{Seedling growth}

The height/age ratio (i.e., mean annual height growth), RCD/age ratio (i.e., mean annual diameter growth) and height/RCD ratio (i.e., slenderness coefficient) was determined for all seedlings. The six seedlings per site were treated as subsamples and were averaged for each of the ratios. All of the ratios were compared between habitats via ANOVA with 10 replicates for each of the three habitats.

\section{Results}

\section{Microenvironment}

Light intensity in White Spruce islands was lower in the northern (SI-N, 54.5\%) versus southern (SI-S, $79.1 \%)$ aspect $(P<0.05)$ (Table 1$)$. Light intensity in the southern island aspect in turn was not significant- ly different from the open prairie conditions (OP-G and OP-J) (all $P>0.05$ ). Light intensity in the aspen grove interior (AG-I, 18.3\%) was significantly less than any of the other habitats (all $P<0.05$ ).

Soil temperature differed among some of the habitats (Table 1). Soil temperature within spruce islands was lower in the northern (SI-N, $13.5^{\circ} \mathrm{C}$ ) versus southern (SI-S, $\left.16.4^{\circ} \mathrm{C}\right)$ aspect $(P<0.05)$. The spruce island habitats (SI-N, SI-S) in turn were not significantly different from soil temperature in the open prairie grass habitat (OP-G, $\left.15.7^{\circ} \mathrm{C}\right)($ all $P>0.05)$. Both the SI-S and the OP-G habitats had significantly greater soil temperature than the open prairie juniper habitat (OP-J, $\left.13.4^{\circ} \mathrm{C}\right)($ all $P<0.05)$. Soil temperature of the aspen grove habitat (AG-I, $10.2^{\circ} \mathrm{C}$ ) was lower than any of the other habitats (all $P<0.05$ ). While surface and air temperature did not differ significantly among the habitats they followed similar relative patterns among the habitats as described for soil temperature.

Although relative air humidity was greatest in aspen groves (AG-I, 36.7\%), lowest in the open prairie (OP$\mathrm{G}, 30.4 \%$; OP-J, $31.8 \%$ ), and intermediate in spruce islands (SI-N, 32.7\%; SI-S, 33.7\%) there were no significant differences in relative air humidity among these habitats (all $P>0.05$ ) (Table 1).

Surface soil moisture in the northern island aspect (SI-N, 7.1\%) was not significantly different from that in the southern aspect (SI-S, 4.7\%) $(P>0.05)$ (Table 1). Soil moisture in the southern island aspect in turn was significantly less than in either the open prairie grass (OP-G, 10.9\%) or aspen grove (AG-I, 8.9\%) (all $P<0.05)$. Surface soil moisture of the open prairie juniper (OP-J, 8.8\%) habitat was not significantly different from the other habitats (all $P>0.05$ ). Average soil moisture of all profile depths in the SI-S (1.8\%) habitat was less than that in the AG-I $(8.0 \%)$ habitat (all $P<0.05$ ) (Table 1).

\section{Seedling growth}

White Spruce seedlings in the open prairie and spruce islands established exclusively amongst Creeping Juniper. Seedlings in aspen groves established exclusively on forest floor litter (i.e., Trembling Aspen leaves). General seedling attributes are shown in Table 2. Mean annual height growth of seedlings did not differ significantly among the three habitats (all $P>0.05$ ) (Figure 2). Mean annual diameter growth differed significantly amongst the three habitats (all $P<0.05$ ) (Figure 3). Open prairie seedlings had the greatest diameter followed by seedlings from spruce islands and then aspen groves. The slenderness coefficient also differed significantly amongst the three habitats (all $P<0.05$ ) (Figure 4). Aspen grove seedlings were most slender, followed by seedlings from spruce islands and then open prairies.

\section{Discussion}

Less exposure to solar radiation was expected under the canopy of aspen groves and spruce islands because of shading. Light conditions under aspen canopy 
TABLE 1. Microenvironmental conditions of Trembling Aspen groves [interior (AG-I) habitat], and White Spruce tree islands [north (SI-N) and south (SI-S) aspect habitat] with adjacent open prairies [grass (OP-G) and juniper (OP-J) habitat]. The lower and upper limits of a $95 \%$ confidence interval of the mean of ten replicates per habitat are shown in parentheses. For each microenvironmental variable, habitats with different letters are significantly different $(P<0.05)$. Except for the temperature data, comparisons were made based on log-transformed data. Microenvironmental variables with no letters for each habitat were not significantly different $(P>0.05)$.

\begin{tabular}{cccccc}
\hline \hline & & & & \\
Variable & & & Habitat & \\
OP-G & OP-J & SI-S & SI-N & AG-I \\
\hline Light $(\%$ PAR $)$ & $100.0 \mathrm{c}$ & $100.0 \mathrm{c}$ & $79.1 \mathrm{c}$ & $54.5 \mathrm{~b}$ & $18.3 \mathrm{a}$ \\
Temp. $\left({ }^{\circ} \mathrm{C}\right)$ & $(100.0,100.0)$ & $(100.0,100.0)$ & $(62.6,100.0)$ & $(44.1,67.2)$ & $(15.9,21.1)$ \\
Soil & $15.7 \mathrm{de}$ & $13.4 \mathrm{bc}$ & $16.4 \mathrm{e}$ & $13.5 \mathrm{~cd}$ & $10.2 \mathrm{a}$ \\
& $(14.1,17.3)$ & $(11.8,14.9)$ & $(15.7,17.1)$ & $(12.1,14.9)$ & $(9.7,10.7)$ \\
Surface & 31.3 & 30.8 & 30.1 & 29.1 & 28.0 \\
& $(28.1,34.5)$ & $(27.9,33.8)$ & $(27.3,32.9)$ & $(27.4,30.7)$ & $(25.6,30.3)$ \\
Air & 31.7 & 31.6 & 29.3 & 30.5 & 29.1 \\
& $(28.7,34.6)$ & $(28.7,34.4)$ & $(26.8,31.9)$ & $(28.9,32.1)$ & $(26.7,31.6)$ \\
RH $(\%)$ & 30.4 & 31.8 & 33.7 & 32.7 & 36.7 \\
SM $(\%$ vol $)$ & $(25.0,37.1)$ & $(26.0,38.8)$ & $(26.7,42.6)$ & $(28.0,38.1)$ & $(30.5,44.1)$ \\
Surface & $10.9 \mathrm{~b}$ & $8.8 \mathrm{ab}$ & $4.7 \mathrm{a}$ & $7.1 \mathrm{ab}$ & $8.9 \mathrm{~b}$ \\
& $(8.7,13.6)$ & $(6.5,11.9)$ & $(2.6,8.5)$ & $(5.1,9.7)$ & $(7.4,10.8)$ \\
Profile & $5.3 \mathrm{ab}$ & $2.4 \mathrm{ab}$ & $1.8 \mathrm{a}$ & $2.0 \mathrm{ab}$ & $8.0 \mathrm{~b}$ \\
& $(2.0,12.0)$ & $(0.4,7.2)$ & $(0.4,4.5)$ & $(0.7,4.4)$ & $(6.2,10.1)$ \\
\hline \hline
\end{tabular}

${ }^{1} \mathrm{PAR}$, photosynthetically active radiation; Temp., temperature; $\mathrm{RH}$, relative air humidity; SM, soil moisture

TABle 2. Attributes of White Spruce seedlings from White Spruce tree islands, open prairies, and Trembling Aspen groves. Standard error of the mean in parentheses.

\begin{tabular}{lccc}
\hline \hline Attribute & Open Prairie & Spruce Island & Aspen Grove \\
\hline Sample size $(n)$ & 60 & 60 & 60 \\
Height $(\mathrm{cm})$ & $50.4(4.9)$ & $49.8(4.6)$ & $69.6(6.7)$ \\
Diameter $(\mathrm{cm})$ & $1.66(0.21)$ & $1.24(0.13)$ & $1.16(0.12)$ \\
Age (year) & $11.4(0.6)$ & $11.9(0.7)$ & $15.1(0.8)$ \\
\hline \hline
\end{tabular}

$(18.3 \%)$ occurred at levels similar to other studies of aspen stands (Archibold et al. 1996: 23\%; Carlson and Groot 1997: 18\%). The dominant overstory White Spruce trees cast shade onto the understory, with more shade on the northern versus southern aspect. The reduced soil temperature of the northern versus southern island aspect as well as the lowest soil temperature in aspen groves indicated that areas with increased shade were also cooler. This was expected since temperature is generally a function of solar radiation (Archibold et al. 1996; Morecroft et al. 1998). Decreased soil temperature may lead to decreased evapotranspirative demands in the aforementioned shaded areas. In our study, soil temperature in aspen groves was $3.2-5.5^{\circ} \mathrm{C}$ less than in the open prairie. Other studies have also reported similar levels of reduced soil temperature in aspen (Archibold et al. 1996: $5^{\circ} \mathrm{C}$ ) and other deciduous stands (Morecroft et al. $1998 ; 2.5^{\circ} \mathrm{C}$ ) compared to adjacent open conditions. Reduced solar radiation has the potential to moderate the microclimate in forest/grassland ecosystems and thus provide a less hostile environment for tree regeneration and growth (Zoltai 1975; Hogg 1994; Breshears et al. 1997; Hogg and Schwartz 1997).

While light and soil temperature varied significantly among different habitats, surface and air temperature as well as relative air humidity did not. Morecroft et al. (1998) also found that a deciduous forest canopy had a greater effect on reducing soil temperature than air temperature. Although air temperature and humidity did not differ significantly among the habitats, the lower level of air temperature in aspen groves (2.5$2.6^{\circ} \mathrm{C}$ lower) versus the open prairie was comparable to that observed in other aspen (Archibold et al. 1996: $1.5^{\circ} \mathrm{C}$ lower; Carlson and Groot 1997: $0.7^{\circ} \mathrm{C}$ ) and deciduous stands (Morecroft et al. 1998: $0.6-0.9^{\circ} \mathrm{C}$ ). Relative humidity was 4.9-6.3\% higher in aspen groves compared to the open prairie. This is comparable to a study in the aspen parkland of Saskatchewan by Archibold et al. (1996). They observed that average relative humidity in the summer was generally $4 \%$ higher inside than outside an aspen grove. Higher air humidity 


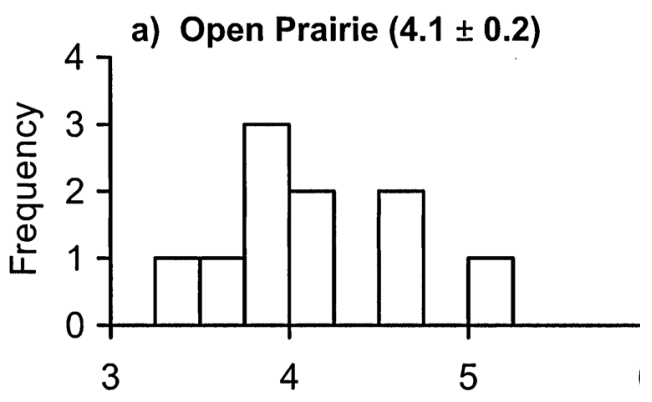

Mean annual height growth ( $\left.\mathrm{cm} \mathrm{yr}^{-1}\right)$

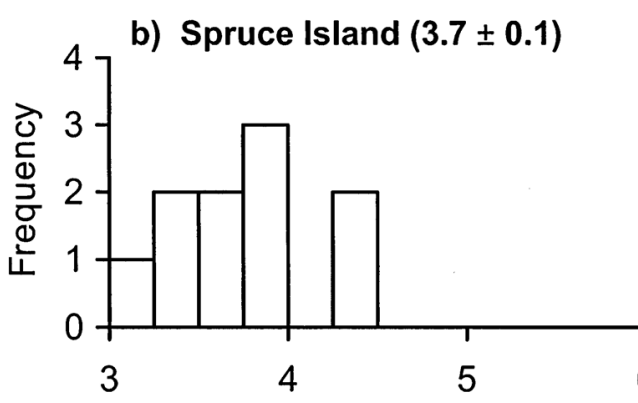

Mean annual height growth $\left(\mathrm{cm} \mathrm{yr}^{-1}\right)$

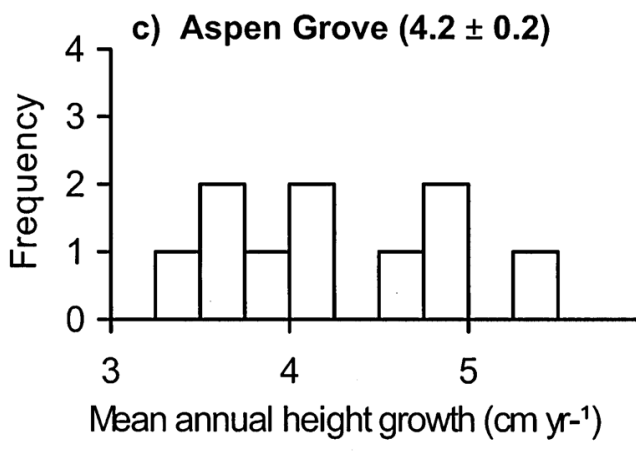

FIGURE 2. Frequency histogram of height/age ratio (i.e., mean annual height growth) of White Spruce seedlings from open prairies (a), White Spruce tree islands (b), and Trembling Aspen groves (c). Mean \pm 1 standard error of the mean of 10 replicates per habitat shown in parentheses. Mean annual height growth did not differ significantly among habitats $(P>0.05)$.

is usually linked to the effects of reduced wind speed and reduced air temperature (Archibold et al. 1996)

Some significant differences in soil moisture were observed among the five habitats. Better moisture retention due to increased shading may explain significantly higher surface and profile soil moisture in aspen groves when compared to SI-S. Due to different degrees of shading, both soil surface and profile moisture were also slightly higher on the northern versus southern aspect of spruce islands. These results support the
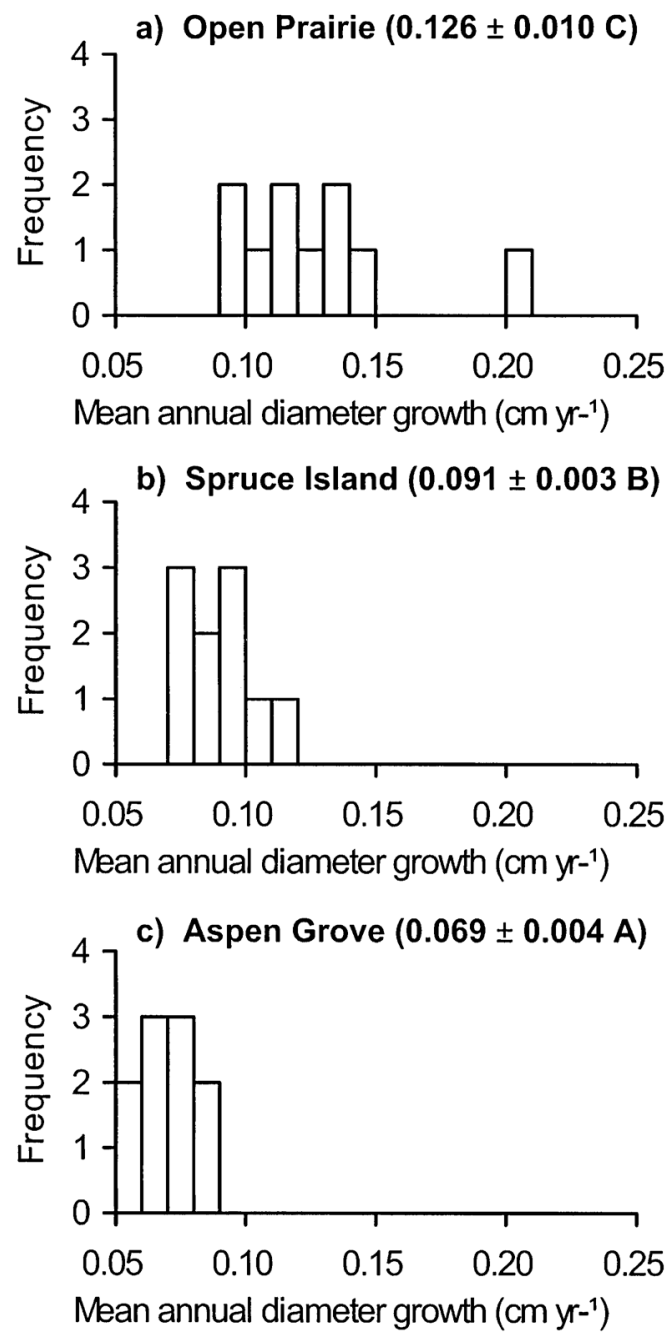

FIGURE 3. Frequency histogram of RCD/age ratio (i.e., mean annual radial growth) of White Spruce seedlings from open prairies (a), White Spruce tree islands (b), and Trembling Aspen groves (c). Mean \pm 1 standard error of the mean of 10 replicates per habitat shown in parentheses, and habitats with different capital letters are significantly different $(P<0.05)$.

hypothesis of soil moisture retention which asserts that soil moisture is expected to be greater in areas of increased shading (Wilson and Kleb 1996; Li and Wilson 1998; Wilson 1998). The significantly higher soil surface moisture found in OP-G, and the lack of significant difference between open prairies and spruce islands or aspen groves in soil profile moisture are, however, difficult to explain. A possible explanation is that tree or shrub canopies, especially those of conifers, intercept rainfall and thus limit the amount of through- 
fall (Vetaas 1992). Although water may also enter soil via stemflow, it has been shown that such water is more likely to infiltrate to deep soil layers to be used by tree species (Parker 1983; Vetaas 1992; Breshears et al. 1997).

Although open prairies represent the worst habitat for White Spruce establishment (Chhin and Wang 2002), they support the best seedling growth. These results support the hypothesis of seed-seedling conflicts which asserts that the habitat requirements for optimal seedling establishment are discordant with that for seedling growth (Schupp 1995). White Spruce did not show any significant differences in height growth amongst the three habitats. In contrast, White Spruce significantly had the greatest diameter growth within the open prairie followed by tree islands and then aspen groves. These results suggest that diameter growth was more responsive to the environmental factors associated with each habitat than height growth. These results are consistent with that of Groot (1999) who reported that diameter growth of young, planted White Spruce was primarily influenced by light availability, whereas height growth exhibited complex relationships with multiple environmental factors.

The larger diameter growth of White Spruce seedlings in the open prairie was not expected given the harsher abiotic microenvironment (i.e., heat stress) of the open prairie compared to the moderated microclimatic conditions within the spruce islands and aspen groves. There are a number of factors which may have contributed to the better diameter growth of seedlings in the open prairie and the lower than expected diameter growth within spruce islands and aspen groves. These factors include the effect of substrate growth conditions, light availability, and morphological adaptations to wind. First, surveying White Spruce seedlings in the open prairie was difficult given the rarity of finding open prairie spruce. Furthermore, those White Spruce individuals that were found grew exclusively in association with Creeping Juniper. Therefore, the better than expected growth in the open prairie may be due to the moderating influence of a Creeping Juniper substrate, and Creeping Juniper is likely providing White Spruce seedlings protective cover from prairie ground fires (Bird 1961). However, seedlings on the northern aspect of spruce islands also established exclusively on juniper. If substrate was a dominant factor influencing diameter growth it is unclear why seedlings from the open prairie and spruce islands would have different diameter growth rates given the same growth substrate.

Corresponding to the diameter growth reduction from OP-J to SI-N to AG-I, the degree of shade increased. The reduced supply of solar radiation could have outweighed the benefits of a moderated microclimate. In other words, while shade is an important moderating microclimatic factor that is conducive to successful White Spruce establishment (Chhin and Wang 2002), shade becomes a limiting factor to subsequent seedling growth. Although ecophysiological
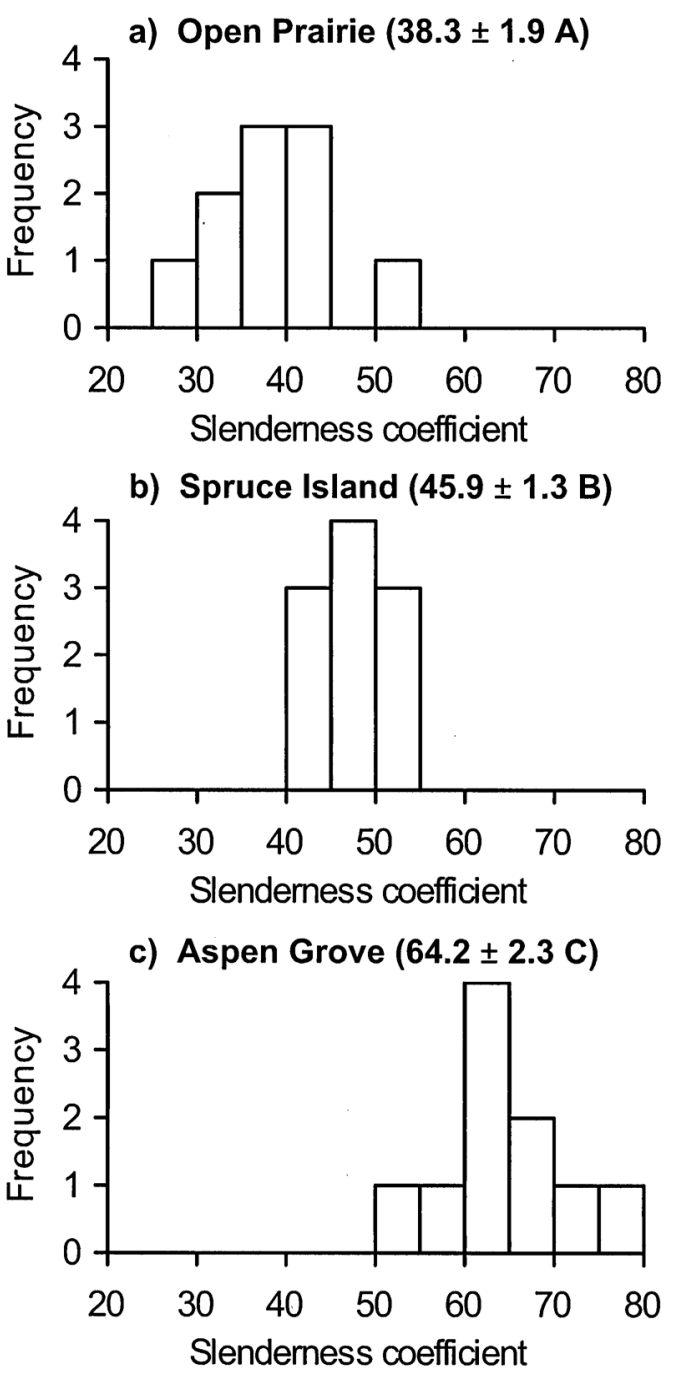

FIGURE 4. Frequency histogram of height/RCD ratio (i.e., slenderness coefficient) of White Spruce seedlings from White Spruce tree islands (a), open prairies (b), and Trembling Aspen groves (c). Mean \pm 1 standard error of the mean of 10 replicates per habitat shown in parentheses, and habitats with different capital letters are significantly different $(P<0.05)$.

studies indicate that White Spruce seedlings generally attain maximal height growth at $40 \%$ full sunlight (Lieffers and Stadt 1994; Lieffers et al. 1996), seedling diameter growth is greatest at full light intensity (Logan 1969). This may explain the reduced diameter growth of seedlings from the northern aspect of spruce islands which was characterized by light levels of $54.5 \%$ of full sunlight. Light levels below $8 \%$ generally results in mortality of White Spruce (Lieffers and Stadt 1994). While light conditions under the aspen canopy $(18.3 \%)$ were greater than this minimal light level, they are 
well below that required for maximal diameter growth. Man and Lieffers (1997) also confirmed that light intensity under an aspen canopy was not sufficient to reach the saturation point although light levels were above the compensation point for White Spruce photosynthesis.

Another likely factor which may explain the discrepancy in diameter growth between the three habitats may be morphological adaptations to the effect of wind. Although wind speed was not examined here, it has been shown in another study in Saskatchewan that wind speed in an aspen grove was reduced to $7 \%$ of that in adjacent prairie (Archibold et al. 1996). Forest openings are generally characterized by greater wind speeds than forest interiors (Carlson and Groot 1997). Wind causes trees to sway and this can lead to morphological adaptations to resist the effect of wind via increased diameter growth particularly at the base of trees (Kozlowski et al. 1991; Telewski 1995).

The effect of shade and wind is further supported by White Spruce being most slender in aspen groves than in tree islands and the open prairie. These results confirmed our morphological observations in the field. White Spruce seedlings from aspen groves were generally tall and thin, while seedlings from the open prairie were short and thick. White Spruce seedlings from spruce islands were intermediate along this morphological continuum. The morphology of White Spruce under aspen canopy is thus suited for concentrating growth in height to counter the effects of overtopping vegetation (Lieffers and Stadt 1994; Lieffers et al. 1996). The morphology of White Spruce in the open prairie is suited for a more robust stature to withstand the effect of winds during summer (Archibold et al. 1996) and wind and snow abrasion during winter. Wind and snow abrasion have been shown to influence the growth form of open grown spruce at its northern limit of distribution at the tree-line in Churchill, Manitoba (Scott et al. 1993).

The possible discordance in habitat requirements of different developmental stages of White Spruce seedlings may potentially influence successional dynamics in a forest-prairie ecotone in the Spruce Woods Provincial Park. For instance, projecting the initial slow degree of White Spruce seedling establishment in the open prairie onto all developmental stages of White Spruce may underestimate the rate of successional expansion of forest onto prairie, since subsequent seedling diameter growth in the open prairie appears to benefit from high light availability. Nonetheless, further research is required to separate the relative effects of high light availability and increased wind exposure on increased diameter growth of White Spruce seedlings in the open prairie. Projecting the initial establishment success of White Spruce under a Trembling Aspen canopy onto all developmental stages of White Spruce may overestimate the rate of successional replacement of Trembling Aspen by White Spruce, since shade appears to outweigh the benefits of a moderated microclimate for diameter growth of White Spruce seedlings under a Trembling Aspen canopy.

In conclusion, higher light and soil temperature conditions occurred within the open versus shaded habitats. The greater diameter growth and decreased slenderness of White Spruce seedlings in the open versus shaded habitats appears to be a result of increased photosynthesis at higher light intensity and may also represent a morphological adaptation to withstand the effect of increased wind exposure. The increased slenderness of White Spruce in the shaded habitats appears to be a morphological adaptation of increasing carbon allocation towards height growth and thus maximizing effective competition for light. While shade is an important moderating microclimatic factor that is conducive to successful White Spruce establishment (Chhin and Wang 2002), our study has shown that at a later developmental stage, shade is a contributing factor towards limiting diameter growth. Our results support the hypothesis that there are conflicting habitat requirements for trees at different developmental stages (Schupp 1995). Thus, in the context of future global warming (IPCC 2007) in a climatically sensitive ecotonal region of the aspen parkland, although moderated microclimates may act as micro-scale refugia or "safe sites" (Harper 1977) for tree seedling establishment, this may be at the expense of reduced growth at a later developmental stage. Models of forest growth in response to climate change should therefore take into account the role of conflicting habitat requirements for trees at different developmental stages.

\section{Acknowledgments}

This study was funded through a Natural Sciences and Engineering Research Council of Canada (NSERC) Postgraduate Scholarship to S. Chhin, and a research grant from Global Forest to G. G. Wang. We thank Drs. R. Staniforth and J. Tardif for their contributions to the initial research proposal. Thanks also go to K. Ryan, R. Klos, and M. Kreiner for their assistance in the field data collection; and K. Schykulski and H. Hernandez of Manitoba Conservation for their logistical support.

\section{Literature Cited}

Archibold, O.W., E. A. Ripley, and D. L. Bretell. 1996. Comparison of the microclimates of a small aspen grove and adjacent prairie in Saskatchewan. American Midland Naturalist 136: 248-261.

Bird, R. D. 1961. Ecology of the aspen parkland of western Canada in relation to land use. Canada Department of Agriculture, Research Branch, Publication 1066, Ottawa, Ontario. 155 pages.

Breshears, D. D., P. M. Rich, F. J. Barnes, and K. Campbell. 1997. Overstory-imposed heterogeneity in solar radiation and soil moisture in a semiarid woodland. Ecological Applications 7: 1201-1215.

Callaway, R. M. 1995. Positive interactions among plants. Botanical Review 61: 306-349. 
Carlson, D. W., and A. Groot. 1997. Microclimate of clearcut, forest interior, and small openings in Trembling Aspen forest. Agricultural and Forest Meteorology 87: 313-329.

Chambers, J. C. 2001. Pinus monophylla establishment in an expanding Pinus-Juniperus woodland: environmental conditions, facilitation and interacting factors. Journal of Vegetation Science 12: 27-40.

Chhin, S., and G. G. Wang. 2002. Spatial and temporal pattern of white spruce regeneration within mixed-grass prairie in the Spruce Woods Provincial Park of Manitoba Journal of Biogeography 29: 903-912.

Chhin, S., G. G. Wang, and J. Tardif. 2004. Dendroclimatic analysis of white spruce at its southern limit of distribution in the Spruce Woods Provincial Park, Manitoba, Canada. Tree-Ring Research 60: 31-43.

Coupland, R. T. 1950. Ecology of mixed prairie in Canada. Ecological Monographs 20: 271-315.

De Steven, D. 1991a. Experiments on mechanisms of tree establishment in old-field succession: seedling emergence. Ecology 72: 1066-75.

De Steven, D. 1991b. Experiments on mechanisms of tree establishment in old-field succession: seedling survival and growth. Ecology 72: 1076-88.

Environment Canada. 2002. Canadian climate normals: 1971-2000. Environment Canada, Ottawa, Ontario.

Farrar, J. L. 1995. Trees in Canada. Fitzhenry and Whiteside Ltd., Markham, Ontario.

Groot, A. 1999. Effects of shelter and competition on the early growth of planted white spruce (Picea glauca). Canadian Journal of Forest Research 29: 1002-1014.

Harper, J. L. 1977. Population biology of plants. Academic Press Inc., London, United Kingdom. 892 pages.

Hogg, E. H. 1994. Climate and the southern limit of the western Canadian boreal forest. Canadian Journal of Forest Research 24: 1835-1845.

Hogg, E. H., and A. G. Schwarz. 1997. Regeneration of planted conifers across climatic moisture gradients on the Canadian prairies: implications for distribution and climate change. Journal of Biogeography 24: 527-534.

IPCC. 2007. Climate change 2007: the physical science basis. Contribution of Working Group I to the Fourth Assessment Report of the Intergovernmental Panel on Climate Change. Edited by S. Solomon, D. Qin, M. Manning, Z. Chen, M. Marquis, K.B. Averyt, M. Tignor, and H. L. Miller. Cambridge University Press, Cambridge, United Kingdom.

Kellman, M., and M. Kading. 1992. Facilitation of tree seedling establishment in a sand dune succession. Journal of Vegetation Science 3: 679-688.

Kozlowski, T. T., P. J. Kramer, and S. G. Pallardy. 1991. The physiological ecology of woody plants. Academic Press, San Diego, California. 657 pages.

Li, X., and S. D. Wilson. 1998. Facilitation among woody plants establishing in an old field. Ecology 79: 2694-2705.

Lieffers, V. J., and K. J. Stadt. 1994. Growth of understory Picea glauca, Calamagrostis canadensis, and Epilobium angustifolium in relation to overstory light transmission. Canadian Journal of Forest Research 24: 1193-1198.

Lieffers, V. J., K. J. Stadt, and S. Navratil. 1996. Age structure and growth of understory white spruce under aspen. Canadian Journal of Forest Research 26: 1002-1007.
Logan, K. T. 1969. Growth of tree seedlings as affected by light intensity. IV. Black spruce, white spruce, balsam fir, and eastern white cedar. Canadian Forest Service, Publication 1256, Ottawa, Ontario. 12 pages.

Man, R., and V. J. Lieffers. 1997. Seasonal photosynthetic responses to light and temperature in white spruce (Picea glauca) seedlings planted under an aspen (Populus tremuloides) canopy and in the open. Tree Physiology 17: 437444.

Morecroft, M. D., M. E. Taylor, and H. R. Oliver. 1998. Air and soil microclimates of deciduous woodland compared to an open site. Agricultural and Forest Meteorology 90: 141-156.

Parker, G. G. 1983. Throughfall and stemflow in the forest nutrient cycle. Advances in Ecological Research 13: 58135.

Rowe, J. S. 1972. Forest regions of Canada. Canadian Forest Service, Department of Fisheries and the Environment, Publication 1300, Ottawa, Ontario. 172 pages.

Schupp, E. W. 1995. Seed-seedling conflicts, habitat choice, and patterns of plant recruitment. American Journal of Botany 82: 399-409.

Schykulski, K., and J. Moore. 1997. Spruce Woods Provincial Park: prairie management plan. Manitoba Department of Natural Resources, Winnipeg, Manitoba.

Scott, P. A., R. I. C. Hansell, and W. R. Erickson. 1993. Influences of wind and snow on northern tree-line environments at Churchill, Manitoba, Canada. Arctic 46: 316323.

Stokes, M. A., and T. L. Smiley. 1996. An introduction to tree-ring dating. The University of Arizona Press, Tucson, Arizona. 73 pages.

Telewski, F. W. 1995. Wind induced physiological and developmental responses in trees. Pages 237-263 in Wind and trees. Edited by M.P. Coutts and J. Grace. Cambridge University Press, Cambridge, United Kingdom.

Vetaas, O. R. 1992. Micro-site effects of trees and shrubs in dry savannas. Journal of Vegetation Science 3: 337-344.

Werner, P. A., and A. L. Harbeck. 1982. The pattern of tree seedling establishment relative to staghorn sumac cover in Michigan old fields. American Midland Naturalist 108: 124-132.

Wilkinson, L. 1990. SYSTAT: the system for statistics. SYSTAT Inc., Evanston, Illinois.

Wilson, S. D. 1998. Competition between grasses and woody plants. Pages 231-254 in Population biology of grasses. Edited by G. P. Cheplick. Cambridge University Press, Cambridge, United Kingdom.

Wilson, S. D., and H. R. Kleb. 1996. The influence of prairie and forest vegetation on soil moisture and available nitrogen. American Midland Naturalist 136: 222-231.

Yamaguchi, D. K. 1991. A simple method for cross-dating increment cores from living trees. Canadian Journal of Forest Research 21: 414-416.

Zoltai, S. C. 1975. Southern limit of coniferous trees on the Canadian prairies. Information Report NOR-X-128, Canadian Forestry Service, Edmonton, Alberta. 12 pages.

Received 2 January 2007

Accepted 9 May 2008 